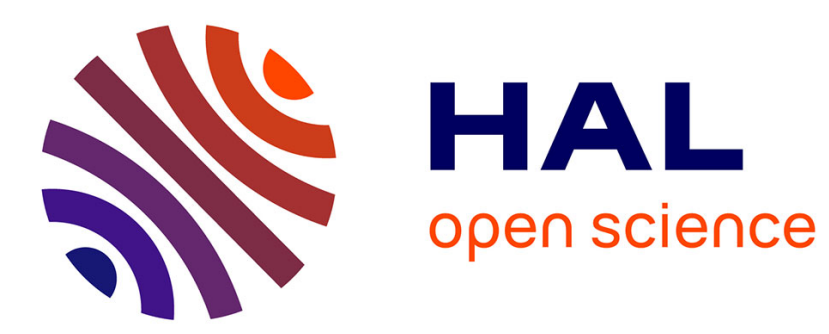

\title{
From Photo Networks to Social Networks, Creation and Use of a Social Network Derived with Photos
}

\author{
Michel Plantié, Michel Crampes
}

\section{To cite this version:}

Michel Plantié, Michel Crampes. From Photo Networks to Social Networks, Creation and Use of a Social Network Derived with Photos. ACM Multimedia Conference, Oct 2010, FIRENZE, Italy. pp.100-110. hal-00804774

\section{HAL Id: hal-00804774 \\ https://hal.science/hal-00804774}

Submitted on 26 Mar 2013

HAL is a multi-disciplinary open access archive for the deposit and dissemination of scientific research documents, whether they are published or not. The documents may come from teaching and research institutions in France or abroad, or from public or private research centers.
L'archive ouverte pluridisciplinaire HAL, est destinée au dépôt et à la diffusion de documents scientifiques de niveau recherche, publiés ou non, émanant des établissements d'enseignement et de recherche français ou étrangers, des laboratoires publics ou privés. 


\section{From Photo Networks to Social Networks, Creation and Use of a Social Network Derived with Photos}

\author{
Michel Plantié \\ EMA-LGI2P \\ Parc Scientifique Georges Besse \\ 30035 Nîmes Cedex, France \\ michel.plantie@ema.fr
}

\author{
Michel Crampes \\ EMA-LGI2P \\ Parc Scientifique Georges Besse \\ 30035 Nîmes Cedex, France \\ michel.crampes@ema.fr
}

\begin{abstract}
With the new possibilities in communication and information management, social networks and photos have received plenty of attention in the digital age. In this paper, we show how social photos, captured during family events, representing individuals or groups, can be visualized as a network that reveals social attributes. From this photo network, a social network is extracted that can help to build personalized albums. The photo network organization makes use of Formal Concept Analysis methods.
\end{abstract}

\section{Categories and Subject Descriptors}

D.2.2 [Design Tools and techniques]: User interface; G.2.2 [Graph Theory]: Graph algorithms

\section{General Terms}

Graph theory, Galois Latice,Social Network

\section{Keywords}

Social Network, Hypergraph, photo, Social Tribe

\section{INTRODUCTION}

With the advent of digital photography and the recent availability of cameras in mobile phones, it is now possible for thousands of photos to be taken in a single year by any one individual. In the past it was typical for a person to capture only a few photos during a particular event. This was substantially due to the photo production photos creating a clear limitation for a photographer. Today, the problem is entirely different thanks to technological advances. Instead one is faced with the problem of how to organize, visualize, browse and share thousands of photos. Within the limits of this paper, we shall only consider collections of social photos. By this, we refer to photos taken during family events or parties with friends. These photos portray individuals or groups of people.

Permission to make digital or hard copies of all or part of this work for personal or classroom use is granted without fee provided that copies are not made or distributed for profit or commercial advantage and that copies bear this notice and the full citation on the first page. To copy otherwise, to republish, to post on servers or to redistribute to lists, requires prior specific permission and/or a fee.

MM'10, October 25-29, 2010, Firenze, Italy.

Copyright 2010 ACM 978-1-60558-933-6/10/10 ...\$10.00.
Considering the important role that digital photos seem to play during social events, it is interesting to explore their capacity to act as a new social language that witnesses social relations. It is also pertinent to explore new applications that can be derived from this language and that may strengthen socialization. Applications like Facebook or Flick'r already manipulate photos within social networks. However, in these cases the networks are built using people and photos act as only passive objects that are voluntarily shared. They do not play an active role in building social networks.

To consider photos as social actors it is necessary to interact with them as active objects. This requirement must be applied at several levels of the photo and social network life cycle. Each level is developed in the sections that follow. Section 2 describes techniques to organize social photos in a way that reveals social relations between people. In order to fulfill this objective, we use Formal Concept Analysis methods for building expressive photo networks, and particularly Concept Hierarchies and Hasse Diagrams. In section 3 we introduce several solutions for eliciting social networks from organized photo collections. Personalized photo albums can be derived from the resulting network and visually hooked to the relevant people in order to check who may receive particular photos. Section 4 presents a practical application of networks building process. Section 4.2 presents how to derive personalized photo albums from these constructed networks.

\section{PHOTOS AND SOCIAL NETWORKS}

Organizing social photos, and eliciting social networks from their content has been a very active research topic recently, although we do not know of papers that integrate photo organization, social network extraction, and personalized album creation. The closest approach that was not known at the time of our research is presented in [8]. The author justifies the fact that photos representing people can be used to elicit social networks. The evaluation method is well grounded and the results agree with ours, although our evaluation method is not as thorough as the one presented in the referenced paper. However, the author does not presents the resulting social network. Consequently there is no support for building and sharing personalized albums. Photos are also indexed in a separate tool that does not make use of their available social content. Finally, there is no real justification for the computation of the derived social network from photo contents. [1] presents a different method with supporting evidence that we extend in this paper. Using Galois Hierarchies to browse photo collections is described in 
some applications such as [2, 3]. Formal Concept Analysis (FCA) and Hasse Diagrams were introduced long ago for representing social networks [4] and remain part of a fruitful field of research such as in [11].

\subsection{The Concept Lattice of indexed photos}

One of the key features we introduce is the ability to organize social photos in a particular network. A Hasse Diagram is used to reveal the social content and elicit the underlying social network. A Hasse Diagram is a well known representation of a Concept Lattice (or Galois Lattice). In Formal Concept Analysis [5], a set of objects with properties (or attributes) can be organized in a lattice of concepts. These concepts contain the objects according to their common properties. In our case, we consider photos as objects and the characters' name on photos as properties. The organization process starts with the formal context : a table with objects as rows and properties as columns. Any entry is marked with valued 1 if the corresponding object possesses the relevant property, and remains unmarked if the object does not possess such an entry. this is formally define in [1]. The next step in the construction of the Concept Lattice is to define concepts. A concept is defined by a pair of subsets : a subset of objects (called the extent) and a subset of properties (the intent) that the objects share. In our case, a concept is a subset of photos that share the same subset of characters' tags (see [1]).

\subsection{Galois Sub-Hierarchy}

To gain more simplicity, it is possible to show reduced extents with reduced intents of concepts. The reduced extent of a concept $(O, A)(O$ a set of objects and $A$ a set of attributes), is the set of objects that belong to $O$ and do not belong to any lower concept, i.e. objects that do not have any other attributes than those in A. Dually, the reduced intent of a concept $(O, A)$ is the set of attributes that belong to $A$ and do not belong to any upper concept. We only keep the concepts that contain objects (photos) where these objects appear only once at their lowest level in the hierarchy (the reduced extent). This act of pruning is called PCL/X as proposed in [7]. It is illustrated with our example in Figure 1. It is now a Galois Sub-Hierarchy as explained in [6]. To be more explicit we call it an Object Galois Sub-Hierarchy (OGSH). It is a much lighter visualization of the data where one only focuses upon the objects (in our case the photos).

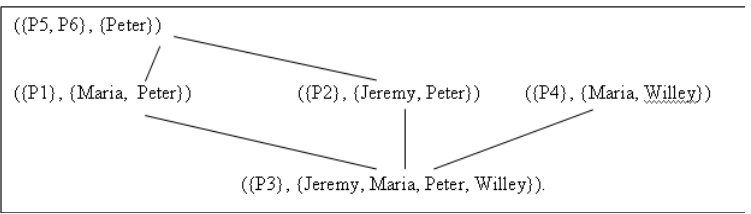

Figure 1: Object Galois Sub-Hierarchy

\section{FROM PHOTOS TO SOCIAL NETWORK}

The Hasse Diagram in Figure 1 reveals the different cooccurrences within photos between people. Each concept shows a particular group of people (the intent of the concept) and contains a collection of photos (the extent of the concept) with this same group of people. From this diagram, we can derive social networks through the computation of the distance, the inverse of proximity, between any pair of people. Different proximity formulas are possible and we shall only introduce a few of them within the limits of this paper. We define the following variables :

$x_{i}$ : is an individual among all people in the photos. $c:$ is a concept in the Hasse Diagram. $C$ : is the number of concepts with cardinality intent $\geq 2$ in the Hasse Diagram.

$\left[c /\left[x_{i}, x_{j}\right]\right]$ : set of concepts containing only $x_{i}$ and $x_{j}$.

$\left[c / x_{i}, x_{j}\right]$ : set of concepts containing at least $x_{i}$ and $x_{j}$.

$\left[c / x_{i}, x_{j}, x_{k}\right]$ : set of concepts containing at least $x_{i}$ and $x_{j}$ and $x_{k}$.

Car[.] : is the cardinality of a particular set.

\subsection{A social network is an hypergraph}

Commonly authors consider that a social network is a graph where vertices are the persons and edges the links between these persons. However, if we analyze more thoroughly the situation, a social network is an hypergraph as [10] suggests. Hypergraphs are mathematical objects generalizing the graph concept, considering that edges link more than one or two vertices up to any number of vertices. A hypergraph $H$ is a couple $(V, E)$ where $V=v 1, v 2, \ldots, v n$ is a non-empty set (usually limited) and $E=E 1, E 2, \ldots, E m$ is a family of the non-empty parties of $V$. The elements of $V$ are the vertices of $H$. The elements of $E$ are the edges of $H$. Hypergraphs precisely correspond to the matrices with 0 or 1 coefficients (where each column holds at leat one 1 value). Every hypergraph $H$ correspond univocaly to the following matrix : $\forall a_{i, j} \in A, a_{i, j}=1$ if $v_{i} \in E_{j}$ and $=0$ if not. A hypergraph is then described by a matrix named incidence matrix.

\subsection{Tribes}

our goal is to create personalized photos albums according to the links between persons being present at an event and share the photos between the persons. Formally we want to find those persons $x_{i}$ (persons appearing on photos) involved for the diffusion of a set of photos. We then introduce a new concept. We call tribe a subset of persons $x_{i}$ involved for a particular personalized album. All persons pertaining to the same tribe are member of a common social network highlighted by the different forms of presence of these persons on different photos. We consider here each couple of person $x, y$, and more precisely the link between $x$ and $y$. Our set of photos and persons is an hypergraph where vertices are persons $x_{i}$ and edges represents tribes, and the links between persons $x_{i}$ are always represented by the photos in the hypergraph. So a tribe is defined as a set of persons following rules. We define here after different membership rules defining different tribes and then we will compare these different tribes. In this model we consider only related occurrences of people in concepts. A concept is represented by a photo that characterizes the intent of the concept, i.e. the group of people.

\subsubsection{The simple force of a couple}

Here, we define the 'frequency' of a couple (two individuals in some form of a relationship) to be the number of occurrences of this couple among the concepts divided by the number of concepts :

$$
\operatorname{SIMPLEFORCE}\left(x_{i}, x_{j}\right)=\frac{\operatorname{Car}\left[c / x_{i}, x_{j}\right]}{C}
$$

This interesting metrics represents how often a couple has been 'captured' by the photographer in different social situations. If the couple is seen in many situations then the relationship between the individuals is rather stable. Howe- 
ver, this distance does not express the strength of the liaison between two people.

\subsubsection{Proximity or couple weighted force}

In agreement with [8] we consider that if more people are in a photo, the links between people are weaker. Consequently to assess the strength of a couple, the number of persons present in photos with this pair should be taken into account. With this in mind, the author in [8] defines a strength of a pair of individuals. We see three pitfalls in this definition. First it is introduced only through common sense and it is not justified. Second, the value is not bounded (for instance with 1). Third, our main concern is that it is applied to all photos. As a consequence, if a large number of photos of the same people have been taken in a row, they will strengthen the links between these people incorrectly. A more evolved formula says that if a couple of persons often appear in small groups, the logic says that this couple is closer than if it often appears in large groups of persons. Proximity formula for a tribe is the sum of inverse numbers of persons being members of concepts containing this tribe, divided by the total number of concepts. Then, the more a couple is diluted in a big number of persons, the weaker the contribution of this concept to the proximity value.

$$
\operatorname{Proximity}\left(x_{i}, x_{j}\right)=\frac{\left(\sum_{k / x_{i}, x_{j} \in c_{k}} \frac{2}{\operatorname{Car}\left[c_{k} / x_{i}, x_{j}\right]}\right)}{C}
$$

\subsubsection{Cohesion of a couple}

Intuitively, we may understand that the above social model does not express some observations automatically extracted from the Hasse diagram. Among them, one is of great interest. The more we see two persons separately, the more they are independent from each other. Conversely, when two persons are always seen together, this strengthen the hypothesis of particular links between them. We call this type of link "cohesion". The couple $\left(x_{i}, x_{j}\right)$ has a strong cohesion when $x_{i}$ et $x_{j}$ are often represented in the same concept with regard to the times they appear in a concept. Cohesion is :

$$
\operatorname{Cohesion}\left(x_{i}, x_{j}\right)=\frac{\operatorname{Car}\left[c / x_{i}, x_{j}\right]}{\operatorname{Car}\left[c / x_{i} \vee x_{j}\right]}
$$

The Cohesion function indicates tribe integrity in a group.

\subsection{Hypergraph Incidence Matrix}

The previous step gives us, a matrix B associated with the hypergraph which shows the relations among persons who where present at a particular event. From this matrix, we now must find tribes. So, we compute the hypergraph incidence matrix $H$ so that $H=T(G)$, with $T(G)$ upper triangular matrix from the first matrix. The i line of $H$ represents a tribe. The j column of $H$ represents a person. For a fixed i, if $h_{i, j}=1$ then person number $\mathrm{j}$ is in the tribe number $i$. We then compute all the different tribes of an event.

\section{PRACTICAL APPLICATION}

We consider an event with five persons who are presents on different photos : Alan (a), Bernard (b), Celine (c), Daniel (d), Emily (e). There are 9 photos. The following table reveals which persons are present on which photos.

\begin{tabular}{|c|c|c|c|c|c|c|c|c|c|}
\hline $\mathrm{C}$ & 1 & 2 & 3 & 4 & 5 & 6 & 7 & 8 & 9 \\
\hline $\mathrm{P}$ & $\mathrm{a}$ & $\mathrm{a}, \mathrm{c}$ & $\mathrm{d}, \mathrm{c}, \mathrm{e}$ & $\mathrm{d}, \mathrm{c}$ & $\mathrm{a}, \mathrm{c}, \mathrm{d}, \mathrm{e}$ & $\mathrm{b}, \mathrm{c}, \mathrm{d}$ & $\mathrm{b}$ & $\mathrm{a}, \mathrm{d}, \mathrm{e}$ & $\mathrm{d}, \mathrm{e}$ \\
\hline
\end{tabular}

Table 1: photos/concepts (C) and persons (P)

\subsection{Forces and tribes}

We consider tribes only when forces are non zero. We may derive 14 tribes if we do not take into account the single persons/photos (special tribes where all forces are 1). Forces computed in last subsection may convey a new balancing variable we will call "tribe Complicity". Complicity may have several meaning :

1. If we consider the maximum tribe force value, this maximum means that empathy between persons is associated with the most happy event that gather them. For photos, a person $x_{i}$ will remember of another person $x_{j}$ more by the fact that they discussed face to face (witnessed by a photo) than by being at one moment in a larger group.

2. If we consider the mean tribe force value, conversely, collusion is a general feeling for the whole party.

3. If we consider the minimum tribe force value, persons in a tribe will remember events of the party when there were together with persons with lesser affinity.

The choice for the "complicity" measure may modify the intension we want to give to a tribe. We will adopt the max value (see table 2 ) for the best moments in a party and will use as a balance for computing the distance from a photo to a tribe as explained in the next section.

\begin{tabular}{|c|c|c|c|c|}
\hline force & Simple & Proximity & Cohesion & Complicity \\
\hline tribe (a,c) & 0,22 & 0,17 & 0,29 & 0,29 \\
\hline tribe (a,d) & 0,22 & 0,13 & 0,25 & 0,25 \\
\hline tribe (a,e) & 0,22 & 0,13 & 0,33 & 0,33 \\
\hline tribe (b,c) & 0,11 & 0,07 & 0,17 & 0,17 \\
\hline tribe (b,d) & 0,11 & 0,07 & 0,14 & 0,14 \\
\hline tribe (c,d) & 0,44 & 0,31 & 0,57 & 0,57 \\
\hline tribe (c,e) & 0,22 & 0,13 & 0,29 & 0,29 \\
\hline tribe (d,e) & 0,44 & 0,31 & 0,66 & 0,66 \\
\hline tribe (a,c,d) & 0,11 & 0,06 & 0,13 & 0,13 \\
\hline tribe (a,c,e) & 0,11 & 0,06 & 0,13 & 0,13 \\
\hline tribe (a,d,e) & 0,22 & 0,13 & 0,25 & 0,25 \\
\hline tribe (b,c,d) & 0,11 & 0,07 & 0,13 & 0,13 \\
\hline tribe (c,d,e) & 0,22 & 0,13 & 0,33 & 0,33 \\
\hline tribe (a,c,d,e) & 0,11 & 0,06 & 0,13 & 0,13 \\
\hline
\end{tabular}

\section{Table 2: tribes and forces
4.2}

The computation of personalized albums follows a simple rule : any photo containing a tribe member is sent to the whole tribes she belongs to. We just have to set up the most interesting rule to choose tribes.

\subsubsection{Rough and weighted photo-tribe distance}

To compute personalized albums, first we compute the distance from a photo to a tribe. We use the Jaccard distance(see [9]), that measures the dissimilarity between two sets. It is computed as the division of the cardinality difference of union and intersection of two sets : $J_{\delta}(A, B)=$ $\frac{|A \cup B|-|A \cap B|}{|A \cup B|}$. Our two sets will be the persons in a photo and the persons in a tribe. We compute first distances (more precisely : complement to 1 of distances) from concepts to tribes for each tribe. When the measure goes higher, the distance is less between them and closeness is more important. This computation also shows that the sum of distances for a tribe is higher when the tribe is greater. We also notice that some concepts (photos) get a summed score more important not entirely related to the number of persons in the photos. We then use the "max" of table 2 to balance the tribe-photo distances. The balanced tribe-photo distance table is shown in table 3 . 


\begin{tabular}{|l|l|l|l|l|l|l|l|l|l|l|}
\hline $\mathrm{C}$ & 1 & 2 & 3 & 4 & 5 & 6 & 7 & 8 & 9 & $\mathrm{~T}$ \\
\hline & $\mathrm{a}$ & ac & dce & dc & acde & bcd & b & ade & de & \\
\hline ac & 0,15 & 0,29 & 0,07 & 0,07 & 0,15 & 0,07 & 0 & 0,07 & 0 & 0,87 \\
\hline ad & 0,13 & 0,08 & 0,06 & 0,08 & 0,13 & 0,08 & 0 & 0,17 & 0,17 & 0,9 \\
\hline ae & 0,17 & 0,22 & 0,17 & 0 & 0,17 & 0 & 0 & 0,22 & 0,22 & 1,16 \\
\hline bc & 0,06 & 0,06 & 0,04 & 0,06 & 0,03 & 0,11 & 0,09 & 0 & 0 & 0,44 \\
\hline cd & 0 & 0,07 & 0,09 & 0,14 & 0,07 & 0,09 & 0 & 0,04 & 0,09 & 0,6 \\
\hline ce & 0 & 0,19 & 0,38 & 0,19 & 0,29 & 0,14 & 0 & 0,14 & 0,38 & 1,71 \\
\hline de & 0 & 0 & 0,19 & 0,19 & 0,15 & 0,07 & 0 & 0,19 & 0,29 & 1,09 \\
\hline acd & 0,22 & 0,44 & 0,33 & 0,44 & 0,5 & 0,27 & 0 & 0,33 & 0,17 & 2,71 \\
\hline ace & 0,04 & 0,09 & 0,07 & 0,03 & 0,1 & 0,03 & 0 & 0,07 & 0,03 & 0,45 \\
\hline ade & 0,04 & 0,03 & 0,07 & 0,03 & 0,10 & 0,03 & 0 & 0,13 & 0,09 & 0,51 \\
\hline bcd & 0 & 0,17 & 0,13 & 0,17 & 0,1 & 0,25 & 0,03 & 0,05 & 0,06 & 1 \\
\hline cde & 0 & 0,04 & 0,13 & 0,09 & 0,10 & 0,40 & 0 & 0,10 & 0,09 & 0,64 \\
\hline acde & 0,08 & 0,17 & 0,25 & 0,17 & 0,33 & 0,2 & 0 & 0,25 & 0,17 & 1,62 \\
\hline
\end{tabular}

Table 3: Weighted distances : concepts (C) - tribes

\subsubsection{Photo distributions}

We have five alternatives from the most restrictive to the most social :

1. Send photos only to the persons in the photos.

2. Send photos to tribes where the threshold of rough distance is higher than a given value. We use to send a photo to a tribe the threshold of 0,5 , indicating that a photo shows a majority of the tribe members.

3. Send photos to tribes where the threshold in table 3 is higher than a given value, like an economic criteria : number of printed photos to send. Let's take 35 photos. The threshold is then 0,15 .

4. Sort in descending order the couples "photo-tribe" according to the measure from table 3 and send photos by fixing a threshold to stop sending photos to tribes. Let's take the threshold of the 10 most important photos according to the couples "photo-tribe". The sorting of the 8 first couples photo-tribe is shown in table 4 .

5. Send all photos to everyone.

Solutions 1 et 5 are commonly used. We will compare all these solutions and more precisely alternatives 2,3 et 4 . In

\begin{tabular}{|c|l|l|l|l|l|l|c|c|}
\hline No & 1 & 2 & 3 & 4 & 5 & 6 & 7 & 8 \\
\hline score & 0,5 & 0,44 & 0,44 & 0,38 & 0,38 & 0,33 & 0,33 & 0,33 \\
\hline photo & acde & ac & dc & cde & de & ade & cde & cde \\
\hline tribe & acde & acd & acd & ce & ce & acd & acd & acd \\
\hline
\end{tabular}

Table 4: 8 leading photo-tribe couples

solution 2 all tribes are selected at least for one photo. For solution 3 , table 5 shows sent photos (concepts). Several tribes are not selected for any photo : (b,c), (c,d), (a,c,e), (a,d,e), $(\mathrm{c}, \mathrm{d}, \mathrm{e})$. We also notice that some photos not representing a whole tribe are still sent to this tribe. According solution 4, several tribes are not selected for any photo : $(\mathrm{a}, \mathrm{c}),(\mathrm{a}, \mathrm{d})$, $(\mathrm{b}, \mathrm{c}),(\mathrm{c}, \mathrm{d}),(\mathrm{a}, \mathrm{c}, \mathrm{e}),(\mathrm{a}, \mathrm{d}, \mathrm{e}),(\mathrm{b}, \mathrm{c}, \mathrm{d}),(\mathrm{c}, \mathrm{d}, \mathrm{e})$. Solution 1 gives

\begin{tabular}{|c|c|c|c|c|c|c|c|c|c|}
\hline Photo & 1 & 2 & 3 & 4 & 5 & 6 & 7 & 8 & 9 \\
\hline Persons & $\mathrm{a}$ & $\mathrm{a}, \mathrm{c}$ & $\mathrm{d}, \mathrm{c}, \mathrm{e}$ & $\mathrm{d}, \mathrm{c}$ & $\mathrm{a}, \mathrm{c}, \mathrm{d}, \mathrm{e}$ & $\mathrm{b}, \mathrm{c}, \mathrm{d}$ & $\mathrm{b}$ & $\mathrm{a}, \mathrm{d}, \mathrm{e}$ & $\mathrm{d}, \mathrm{e}$ \\
\hline A & $\mathrm{X}$ & $\mathrm{X}$ & $\mathrm{X}$ & $\mathrm{X}$ & $\mathrm{X}$ & $\mathrm{X}$ & & $\mathrm{X}$ & $\mathrm{X}$ \\
\hline B & & $\mathrm{X}$ & & $\mathrm{X}$ & & $\mathrm{X}$ & & & \\
\hline C & $\mathrm{X}$ & $\mathrm{X}$ & $\mathrm{X}$ & $\mathrm{X}$ & $\mathrm{X}$ & $\mathrm{X}$ & & $\mathrm{X}$ & $\mathrm{X}$ \\
\hline $\mathrm{D}$ & $\mathrm{X}$ & $\mathrm{X}$ & $\mathrm{X}$ & $\mathrm{X}$ & $\mathrm{X}$ & $\mathrm{X}$ & & $\mathrm{X}$ & $\mathrm{X}$ \\
\hline E & $\mathrm{X}$ & $\mathrm{X}$ & $\mathrm{X}$ & $\mathrm{X}$ & $\mathrm{X}$ & $\mathrm{X}$ & & $\mathrm{X}$ & $\mathrm{X}$ \\
\hline
\end{tabular}

Table 5: Photos sent to persons (Jaccard distance) 21 photos, solution 2 gives 38 photos, solution 3 gives 35 photos, solution 4 gives 27 photos and complete solution 5 gives 45 photos. Each solution has a different selection strategy : either an "anti-social" criteria, either a "semi-social" criteria, either an economic criteria : the total number of printed photos, either a semantic criteria, or a totally social criteria. We now have a tool for computing personalized albums which may be used in a complete automatic way, or as a semi-automatic use in a manual process. The different strategies presented are amendable and show the richness of our selection model. Many ways are still to be explored.

\section{CONCLUSION}

Many improvements are possible, and our models may be extended to take into account semantics when extracting the social network. Like the bias of the photographer, who may not be impartial or the photo manufacturer or the photo sender. Our future works will explore these models, with more profound testing. Particularly the scaling factor will be studied when using hundreds of photos or to reveal the social networks evolution in time and melting several social events. We will also use the principles exposed here to probe another field : building social networks from semantic analysis of shared documents between persons.

\section{REFERENCES}

[1] M. Crampes, J. de Oliveira-Kumar, S. Ranwez, and J. Villerd. Visualizing social photos on a hasse diagram for eliciting relations and indexing new photos. IEEE Trans. Vis. Comput. Graph., pages 15 (6) 985-992, 2009.

[2] P. Eklund, J. Ducrou, and T. Wilson. An intelligent user interface for browsing and search mpeg-7 images using concept lattices. Proc of the 4 th International Conference on Concept Lattices and Their Applications, LNAI, Springer-Verlag, 2006.

[3] S. Ferré. Camelis : Organizing and browsing a personal photo collection with a logical information system. Proc. of the 5th International. Conference on. Concept Lattices and Their Applications, pages 112-123, 2007.

[4] L. Freeman and D. White. Using galois lattices to represent network data. Sociological Methodology, $23: 127-146,1993$.

[5] B. Ganter and R. Wille. Formal concept analysis. Mathematical Foundations, Springer, 1999.

[6] R. Godin and T. Chau. Comparaison d'algorithmes de construction de hiérarchies de classes. L'objet, 5(3/4), 1999.

[7] R. Godin, G. Mineau, and R. Missaoui. Incremental structuring of knowledge bases. Proceedings of the International Knowledge Retrieval, Use, and Storage for Efficiency Symposium (KRUSE'95), Santa Cruz, 179-198, 1995.

[8] S. A. Golder. Measuring social networks with digital photograph collections. Hypertext and Hypermedia ACM Conference. June 19-21. Pittsburgh, Pennsylvania, 2008.

[9] L. KAUFMAN, P. ROUSSEEUW, and J. B. P. Finding groups in data: An introduction to cluster analysis. WILEYInterscience, 1990.

[10] P. Mika. Ontologies are us : A unified model of social networks and semantics. In International Semantic Web Conference, pages 522-536, 2005.

[11] C. Roth and P. Bourgine. Lattice-based dynamic and overlapping taxonomies : The case of epistemic communities. Scientometrics (impact factor : 1.74), 69(2) :429-447, 2006. 